\title{
ANALISIS HARGA PASOK, KUALITAS LAYANAN DAN KEMUDAHAN TERHADAP LOYALITAS PETANI TEBU GONDANGLEGI KAB UPATEN MALANG
}

\author{
Yusaq Tomo Ardianto \\ Fakultas Ekonomi Jurusan Manajemen Universitas Merdeka Malang \\ Jl. Terusan Raya Dieng 62-64 Malang \\ E-Mail : yutodito@yahoo.co.id
}

\begin{abstract}
This research was conducted in August 2009. Commodities have certain sugarcane proved good prospects for sugar prices from year to year continue to increase. This is expected to have a balance between sugarcane farmers' income with the increase in sugar prices. In general, the purpose of this study was to test how much influence the supply price policy, quality of services and facilities conducted by the New Krebet PG for sugarcane farmers around South Malang Regency. Results showed that the policy affects the supply price of sugarcane farmers and the loyalty of service quality did not provide a positive impact on the loyalty of sugarcane farmers. This research hopes to PG policy New Krebet always siding with the interests and the fate of sugarcane farmers and factory environments around the intertwined relationships of a harmonious partnership between sugar cane farmers by the factory.
\end{abstract}

Kata kunci : harga, kualitas pelayanan, kemudahan, loyalitas, petani tebu

Tanaman tebu di Jawa Timur khususnya Kabupaten Malang merupakan produk pertanian terbesar setelah padi, jagung, kopi serta tanaman lainnya. Masyarakat di Kabupaten Malang memiliki mata pencaharian bertani sesuai dengan kondisi tanah, iklim dan cuaca. Kebanyakan dari masyarakat di daerah tersebut memilih menanam tebu sebagai komoditas unggulan. Tanaman tebu merupakan jenis tanaman yang mudah ditanam serta memiliki tingkat risiko yang rendah dari ancaman fluktuasi harga, hama serta penyakit tanaman lainnya. Berbeda dengan tanaman padi dan jagung misalnya, walaupun kedua tanaman tersebut merupakan makanan pokok bagi masyarakat namun pada waktu tertentu secara ekonomi tidak dapat memberikan keuntungan yang optimal 
bagi petaninya. Berbeda dengan tebu memiliki nilai ekonomis yang cukup baik bila dibandingkan dengan komoditas tanaman pertanian lainnya. Risiko menanam tebu terletak pada masa tanam yang cukup lama yakni kurang lebih satu tahun berbeda dengan komoditas seperti padi, jagung, sayur-sayuran dan sejenisnya.

PG Krebet Baru adalah pabrik yang menghasilkan gula pasir warna putih, berlokasi di Kabupaten Malang. Untuk memenuhi kebutuhan bahan-bakunya, PG Krebet Baru menawarkan jasa giling tebu untuk dijadikan gula kepada petani tebu disekitar wilayah areal/lokasi pabrik. Untuk memotivasi pembeli jasa (petani tebu), perusahaan menetapkan kadar rendemen gula yang menarik dan harga gula perkilo yang transparan. Sepuluh persen dari nilai gula yang dihasilkan adalah miliki petani sedangkan $90 \%$ sisanya dibeli oleh pabrik, sehingga petani yang membeli jasa PG Krebet Baru akan memperoleh gula sebanyak $10 \%$ dan $90 \%$ nya berupa uang.

Hasil wawancara peneliti kepada para petani di lokasi Kabupaten Malang diperoleh kesimpulan bahwa petani bebas memilih untuk membeli jasa produksi pada Pabrik Gula di manapun baik di sekitar lahan tebu milik petani maupun diluar yang berjauhan dengan lahan pertanian mereka. Kondisi ini berdampak bagi penawaran jasa oleh PG Krebet Baru untuk berkompetisi dengan Pabrik Gula lain seperti PG Mojopanggung, PG Ngadiredjo, dan terutama PG Kebon Agung agar petani tebu di Kabupaten Malang supaya memilih dan mempercayai perusahaan PG Krebet Baru untuk mencapai target produksi setiap periode giling. Kunci utama bagi Manajemen PG Krebet Baru adalah bagaimana mengupayakan petani tebu menjadi pembeli loyal perusahaan. Jika kebanyakan petani tebu loyal terhadap PG Krebet Baru maka pencapaian target produksi PG Krebet Baru akan tercapai, atau bahkan mencapai prestasi perolehan bahan baku tebu sehingga keuntungan PG Krebet Baru menjadi optimal. Disebutkan oleh Griffin dalam Hurriyati (2005:129) tentang loyalitas adalah pelanggan yang lebih mengacu pada wujud perilaku dari unit-unit pengambilan keputusan untuk melakukan transaksi secara terus-menerus terhadap barang/jasa suatu perusahaan yang dipilih. Oleh Indrayani ( 2004:168-179) bahwa loyalitas mempunyai beberapa tingkatan dari loyalitas paling rendah hingga loyalitas yang paling tinggi, semakin tinggi loyalitas mereka sulit untuk dipengaruhi oleh 
berbagai faktor seperti perubahan harga, produk dll. Berkaitan dengan definisi tersebut, PG Krebet Baru mengharapkan petani tebu melakukan transaksi secara terus-menerus selama perionde giling dari tahun ke tahun dengan perusahaan, dan diharapkan pula petani tebu mau merekomendasikan kepada petani tebu lain tentang kebaikan pabrik, mengikuti petunjuk/arahan dari manajemen pabrik serta memahami kesulitan-kesulitan yang dialami perusahaan. Point-point tersebut menentukan tingkat loyalitas petani tebu dan memberi celah bagi peneliti untuk melakukan studi lebih lanjut. Loyalitas akan muncul jika terjadi pengalaman tentang kepuasan bagi petani tebu. Faktor kepuasanlah juga menentukan loyalitas petani tebu sebagai pemasok bahan baku utama pabrik. Kepuasan menurut Kotler dalam Teguh (1997:36) adalah perasaan senang seseorang yang berasal dari perbandingan antara kesannya terhadap kinerja (atau hasil) suatu produk dan harapan-harapannya. Petani tebu yang merasakan puas terhadap pelayanan PG Krebet, akan mengambil keputusan untuk membeli jasa produksi kepada PG Krebet Baru dengan mempertimbangkan pengalaman terdahulu, sehingga bagi PG Krebet Baru bahwa proses pembelajaran dalam hal pelayanan guna memperoleh kepuasan petani tebu menjadi sesuatu yang dianggap penting. Disebutkan oleh Irawan (2002:37-76) bahwa faktor-faktor loyalitsa dapat dipengaruhi oleh beberapa variabel misalnya harga, kualitas pelayanan, serta perolehan kemudahan-kemudahan. Sampai dengan sekarang PG Krebet Baru melakukan upaya manajemen dalam rangka ingin mewujudkan loyalitas petani tebu melalui penetapan harga gula bagian petani, penetapan rendemen gula, serta melakukan aktivitas pelayanan dan kemudahan-kemudahan sebagai pemasok bahan baku tebu. Penetapan harga lelang bagian petani harus sesuai dengan harapan mereka. Jika melebihi harapan mereka maka petani tebu akan menjadi puas dan akhirnya loyal, demikian pula dengan penetapan rendemen gula bagi hasil juga diharapkan dapat memuaskan petani tebu dan menciptakan loyalitas. Pabrik melakukan periode giling dimulai pada bulai Mei hingga Desember, dengan mempertimbangkan faktor pesaing dan curah hujan, PG Krebet Baru berupaya menetapkan penawaran rendemen gula dan harga lelang gula petani pada tingkat kompetitif. Disamping itu PG Krebet juga melakukan upaya upaya pelayanan dan kemudahan-kemudahan bagi petani tebu sebagai pemasok. PG Krebet Baru juga 
melakukan kegiatan pelayanan dalam hal penyediaan bibit, pupuk serta bantuan pinjaman modal serta memberikan kemudahan-kemudahan administrasi sebagai pemasok bahan baku tebu. Disebutkan oleh Nirwanto (2000:23) dalam Mc Carthy bahwa pelanggan loyal perlu diciptakan ikatan yang kuat antara organisasi dengan pelanggan agar mereka tidak berpindah kepada pesaing anda.

Hasil observasi peneliti terhadap manajemen PG Krebet Baru memberikan informasi bahwa petani tebu yang memiliki sifat loyal yakni petani tebu yang membeli jasa produksi kepada PG Krebet Baru secara konsisten, memahami kesulitan-kesulitan pabrik gula, serta mengikuti petunjuk budi daya pasca panen. Untuk itu, PG Krebet Baru perlu melakukan upaya-upaya strategis guna untuk memuaskan kepuasan petani tebu guna mewujudkan loyalitasnya.

Berdasar studi observasi di lapangan oleh peneliti, bahwa jumlah pasokan tebu pada PG Krebet Baru disebabkan oleh perilaku petani tebu kebanyakan di lokasi Kabupaten Malang memiliki perilaku loyal terhadap perusahaan. Mereka loyal karena telah menikmati beberapa fasilitas dan pelayanan PG Krebet Baru. Faktor persepsi penawaran harga jasa produksi PG Krebut Baru, kualitas layanan perusahaan, tingkat emosi petani, serta kemudahan-kemudahan yang diberikan oleh perusahaan sangat mempengarui loyalitas petani tebu untuk membeli jasa produksi PG Krebet Baru. Hal ini sesuai dengan pendapat Irawan (2002:37-76) bahwa faktor-faktor kepuasan dapat dijelaskan melalui variabel misalnya harga, kualitas pelayanan dan kemudahan. Oleh sebab itu penawaran harga PG Krebet Baru harus dapat memberikan nilai harapan yang baik bagi petani tebu demikian pula untuk kualitas layanan dan kemudahan-kemudahan. Disebutkan oleh Irawan (2002:37-76) bahwa kualitas pelayanan dapat diukur melalui indikator realibility (keandalan), responsiveness (ketanggapan), assurance (jaminan), empathy (empati) dan tangible (bukti fisik). Beberapa variabel tentang kualitas pelayanan tersebut menarik untuk diuji/diteliti guna mengetahui seberapa besar tingkat loyalitas petani tebu terhadap PG Krebet Baru. 


\section{TINJAUAN TEORI}

Oliver dalam Hurriyati (2005: 128-129) mengungkapkan definisi loyalitas sebagai berikut : " komitmen untuk berlangganan kembali atau melakukan transaksi ulang produk/jasa, terpilih secara konsisten dimasa yang akan datang, meskipun ada pengaruh situasi dan usaha-usaha pemasaran mempunyai potensi untuk menyebabkan perubahan perilaku.

Menurut Griffin dalam Hurriyati (2005:129) tentang pelanggan yang loyal adalah :" Pelanggan yang lebih mengacu pada wujud perilaku dari unit-unit pengambilan keputusan untuk melakukan transaksi secara terus menerus terhadap barang/jasa suatu perusahaan yang dipilih."

Disebutkan diatas dalam Profil PT Rajawali Nusantara Indonesia (2003;10) menyikapi makna tentang pelanggan adalah para pemasok bahan-baku utama, dalam hal ini adalah para petani tebu. Sehubungan dengan definisi yang disebutkan oleh Griffin dalam Hurriyati (2005:129) maka makna tentang pelanggan yang loyal yaitu Pemasok ( dalam hal ini adalah petani tebu) yang lebih mengacu pada wujud perilaku dari unit-unit pengambilan keputusan untuk melakukan transaksi secara terus menerus terhadap barang/jasa suatu perusahaan yang dipilih, meskipun ada pengaruh situasi/kondisi dan usaha-usaha pemasaran dari perusahaan pesaing yang mempunyai potensi untuk menyebabkan perubahan perilaku

Pelanggan yang loyal merupakan aset penting bagi perusahaan, hal ini dapat dilihat dari karakteristik yang dimilikinya, sebagaimana diungkapkan Griffin dalam Hurriyati (2005:130), pelanggan yang loyal memiliki karakteristik sebagai berikut (1) Melakukan pembelian secara teratur ( makes regular repeat purchase), (2) Membeli diluar lini produk/jasa (purchase across product and service lines), (3) Merekomendasikan produk/jasa (refers other), (4) Menunjukkan kekebalan dari daya tarik produk sejenis dari pesaing (demostrate an immunity to the full the competiton) 
Loyalitas diperoleh tergantung dari kualitas jasa dan produk yang ditawarkan. Irawan (2002;37-76) menyebutkan tentang faktor-faktor yang dapat mempengaruhi loyalitas melalui lima driver utama yaitu :

a. Driver pertama adalah kualitas produk

Pelanggan merasa puas setelah menggunakan produk tersebut. Kualitas produk ini adalah dimensi yang global. Ada enam elemen yang menjelaskan kualitas produk yaitu performance, durability, feature, reliability, consistency dan design.

Performance berhubungan dengan fungsi utama dari suatu produk yang dijanjikan oleh produsen.

Dimensi performance dan reliability sepintas mirip tetapi mempunyai perbedaan yang jelas. Reliability tebih menunjukkan pada kemampuan produk, sedangkan performance ditekankan pada kinerja produk sesuai dengan spesifikasi yang dijanjikan.

Dimensi feature / fitur dikatakan sebagai aspek sekunder meliputi tampilan pilihan yang ditawarkan oleh produsen.

Durability menyatakan keawetan terhadap produk baik terhadap siklus, teknis maupun waktu.

Conformance menunjukkan seberapa jauh produk dapat menyamai standar atau spesifikasi tertentu. Produk yang mempunyai conformance tinggi berarti produknya sesuai dengan standar yang ditentukan. Salah satu aspek dari conformance adalah konsistensi.

b. Driver kedua adalah harga

Untuk pelanggan yang sensitif, harga merupakan sumber kepuasan yang penting. Pelanggan memperoleh value for money yang tinggi jika harga yang ditawarkan memadai. Disebutkan oleh Tjiptono (2002:151) menyatakan bahwa harga merupakan satuan moneter atau ukuran lainnya yang ditukarkan agar memperoleh hak kepemilikan atau penggunaan atas suatu barang atau jasa. Demikian pula oleh 
Simamora (2000:574) harga adalah jumlah uang yang dibebankan atau dikenakan atas sebuah produk atau jasa.

c. Driver ketiga adalah kualitas pelayanan (service quality)

Sevice quality sangat bergantung pada tiga hal yaitu sistem, teknologi dan manusia. Faktor manusia memegang kontribusi sekitar $70 \%$ sehingga tidak mengherankan, kepuasan terhadap kualitas pelayanan sulit untuk ditiru.

Kualitas pelayanan juga merupakan driver yang mempunyai banyak dimensi. Salah satu konsep service quality yang populer disebut ServQual, yang dikembangkan oleh Parasuraman, Berry dan Zeithaml. Konsep ini memiliki lima dimensi yakni reliability, responsiveness, assurance, empathy dan tangible.

Menurut Olsen dan Wyckoff dalam Yamit (2002:22) kualitas pelayanan adalah perbandingan antara harapan konsumen dengan kinerja produk jasa.

d. Driver keempat adalah faktor emosi (emotional factor)

Emosi yakni bentuk motif/dorongan untuk melakukan sesuatu. Sehingga emosi lebih dekat dengan persepsi positip dari individu atau kelompok terhadap perusahaan. Persepsi positip ini terjadi karena pengalaman masa lalu, sehingga muncul perasaan rasa bangga, rasa percaya diri, aman, simbol sukses dan menjadi bagian dari kelompok orang penting.

e. Driver kelima adalah kemudahan

Kemudahan yakni sesuatu yang tidak menjadi hambatan bagi pelanggan untuk melakukan transaksi. Kemudahan merupakan faktor kepuasan bagi pelanggan Pelanggan merasa puas jika mereka merasa relatif mudah, nyaman, dan efisien. Memperoleh kemudahan karena pelayanan serta penawaran-penawaran yang lebih menarik.

Pengukuran kualitas jasa dalam model Servqual didasarkan pada skala multi item yang dirancang untuk mengukur harapan dan persepsi pelanggan. Menurut Munawaroh 
(2000:17) dalam Parasuraman terdapat lima dimensi yang menjelaskan kualitas pelayanan seperti :

a. Reliabilitas (reability) yakni kemampuan memberikan layanan yang dijanjikan dengan segera, akurat dan memuaskan.

b. Daya tanggap (responsiveness) yakni keinginan para staf untuk membantu para pelanggan dan memberikan layanan dengan tanggap.

c. Jaminan (assurance) mencakup pengetahuan, kompetensi, kesopanan dan sifat dapat dipercaya yang dimiliki para staf; bebas dari bahaya atau keragu-raguan.

d. Empati (empathy), meliputi kemudahan dalam menjalin relasi, komunikasi yang baik, perhatian pribadi dan pemahaman atas kebutuhan individu para pelanggan.

e. Bukti fisik (tangibles) meliputi fasilitas fisik, perlengkapan, pegawai dan sarana komunikasi.

\section{METODE PENELITIAN}

\section{Desain penelitian}

Jenis penelitian ini adalah penelitian asosiatif/hubungan, menggunakan desain penelitian survey. Penelitian asosiatif atau hubungan adalah penelitian yang bertujuan untuk mengetahui hubungan antara dua variabel atau lebih (Sugiono, 2000:11). Penelitian ini mendeskripsikan tentang faktor-faktor yang mempengaruhi loyalitas petani tebu dan menjelaskan faktor nama yang memberikan pengaruh dominan terhadap loyalitas petani tebu.

\section{Populasi dan sampel}

Subject penelitian adalah petani tebu di wilayah Malang Selatan seperti daerah Gondanglegi, Pagelaran, Gedangan dan Donomulyo. Pendekatan penelitian ini menggunakan non probability sampling, dengan alasan besarnya popolasi tidak diketahui (Ferdinand, 2006:231). Roscoe (1975) dalam Ferdinand (2006:225) diperoleh beberapa pedoman untuk menentukan sampel yakni bila sampel dibagi - bagi menjadi beberapa sub sampel, maka minimum 30 pengamatan untuk setiap kategori sub sampel sudah memadai. 
Jumlah sub sampel penelitian ini didasarkan atas wilayah sebanyak 4 sub yakni Gondanglegi, Pagelaran, Gedangan dan Donomulyo maka diambil sampel sebanyak 30X4 yakni 120 sampel.

\section{Identifikasi variabel dan definisi operasional}

a. Variabel bebas yakni harga pasok (X1), kualitas layanan (X2) dan kemudahan (X3)

1. Harga pasok (X1) adalah persepsi petani tebu atas pengorbanan yang dikeluarkan dibandingkan dengan hasil yang diperoleh. Kebijakan harga pasok diukur oleh item

- Penawaran penetapan harga gula bagian petani sesuai dengan pengorbanan petani

- Penetapan harga gula bagian petani sudah obyektif.

- Jumlah uang yang diterima petani tebu sesuai dengan harapan

2. Kualitas layanan (X2) adalah bentuk kegiatan yang dilakukan oleh PG Krebet Baru guna memenuhi harapan kepuasan petani tebu sebagai pemasok bahan baku perusahaan. Diukur dengan indikator : Tanggapan, Empati, Bukti Fisik, Keandalan dan Jaminan

3. Kemudahan (X3) adalah upaya PG Krebet Baru untuk melayani petani tebu agar mereka memperoleh kemudahan administrasi, mudah dalam memanfaatkan fasilitas pabrik dan mudah melakukan proses transaksi. Diukur dengan indikator seperti : Kemudahan administrasi dan kemudahan fasilitas pabrik.

b. Variabel tergantung yakni loyalitas petani tebu $(\mathrm{Y})$

Adalah bentuk perilaku petani tebu sebagai pemasok bahan baku dengan cara melakukan transaksi secara terus menerus melalui kegiatan pembelian jasa PG Krebet Baru. Diukur dengan item seperti :

- Dalam kondisi apapun tetap menjadi pemasok tebu

- Merasa senang sebagai pemasok PG Krebet Baru

- Mau merekomendasikan kebaikan PG Krebet Baru terhadap petani tebu lain

- Mau mengikuti aturan main Pabrik 
- Mau mengikuti petunjuk-petunjuk/arahan yang diberikan PG Krebet Baru

- Memahami kesulitan PG Krebet Baru yang telah menjadi mitra usaha

- Mau menyampaikan keluhan kepada PG Krebet Baru

\section{Teknik analisa data}

Data primer penelitian ini adalah jawaban atas pilihan respoden dengan menggunkaan skala Likert. Pilihan 1 adalah sangat tidak setuju hingga pilihan 5 yakni sangat setuju. Penelitian ini menggunakan 38 item pertanyaan. Setelah data primer terkumpul dilakukan uji Validitas dan Reliabilitas. Untuk menjawab tujuan penelitian maka digunakan model regresi linier berganda $Y=a+b X 1+b X 2+b X 3+e$, Uji asumsi klasik, Uji F, uji t dan statistik diskriptif.

\section{HASIL PENELITIAN}

Hasil analisis terhadap tigapuluh delapan item pertanyaan memperoleh hasil yang valid ditunjukkan dengan uji statitistik bahwa nilai koefisien korelasi setiap item pertanyaan lebih besar dari $\mathrm{t}$ tabel. Demikian pula nilai Alhpa Chronbach untuk masingmasing variabel lebih besar dari nilai $r_{\text {tabel, }}$ artinya menunjukkan reliabel. Hasil diskripsi untuk setiap item dan indikator di-interpretasi-kan dengan menggunakan nilai mean yang dihasilkan. Hasil nilai mean setiap indikator dan variabel penelitian seperti di bawah ini :

\section{Tabel 1}

Hasil Nilai Rata-rata Indikator dan Variabel Penelitian

\begin{tabular}{|c|c|c|c|c|}
\hline Variabel & Indikator & Butir & $\begin{array}{l}\text { Total } \\
\text { Mean }\end{array}$ & $\begin{array}{c}\text { Hasil } \\
\text { Interpretasi }\end{array}$ \\
\hline Harga $\left(X_{1}\right)$ & Harga & 3 item & 3.39 & Cukup / biasa \\
\hline \multirow{5}{*}{$\begin{array}{c}\text { Kualitas Pelayanan } \\
\qquad\left(\mathrm{X}_{2}\right)\end{array}$} & Daya tanggap $\left(\mathrm{X}_{21}\right)$ & 10 item & 3.51 & \multirow{5}{*}{$\begin{array}{c}\text { Cukup / biasa } \\
\quad 3.174\end{array}$} \\
\hline & Empati $\left(X_{22}\right)$ & 2 item & 3.29 & \\
\hline & Bentuk fisik $\left(X_{23}\right)$ & 3 item & 3.31 & \\
\hline & Keandalan $\left(X_{24}\right)$ & 2 item & 2.99 & \\
\hline & Jaminan $\left(X_{25}\right)$ & 2 item & 2.77 & \\
\hline \multirow{2}{*}{ Kemudahan $\left(X_{3}\right)$} & $\begin{array}{l}\text { Kemudahan administrasi } \\
\left(\mathrm{X}_{41}\right)\end{array}$ & 5 item & 2.76 & \multirow[t]{2}{*}{$\begin{array}{c}\text { Cukup/biasa } \\
3.27\end{array}$} \\
\hline & Kemudahan fasilitas $\left(\mathrm{X}_{42}\right)$ & 4 item & 3.79 & \\
\hline Loyalitas $\left(X_{5}\right)$ & Loyalitas & 7 item & 3.78 & baik \\
\hline
\end{tabular}


Sumber: Data primer diolah

Hasil pengujian regresi linier berganda, asumsi klasik diringkas seperti pada tabel dibawah ini :

Tabel 2:

Rekapitulasi Hasil Perhitungan

\begin{tabular}{|c|c|c|c|c|c|}
\hline Variabel bebas & $\begin{array}{c}\text { Koefisien } \\
\text { Regresi }\end{array}$ & $\begin{array}{l}\text { Prob. } \\
\text { Sig. } t\end{array}$ & VIF & Sig. Res & Keterangan \\
\hline $\mathrm{X}_{1}$ - Harga & 0.475 & 0.000 & 9,808 & 0.302 & Signifikan \\
\hline $\mathrm{X}_{2}-$ Kualitas Pelayanan & 0.057 & 0.192 & 23,396 & 0.509 & Tdk Signifikan \\
\hline$X_{3}-$ Kemudahan & 0.385 & 0.000 & 28,005 & 0.706 & Signifikan \\
\hline Konstanta (a) & \multicolumn{5}{|l|}{7.244} \\
\hline Durbin Watson (DW) & \multicolumn{5}{|l|}{1.833} \\
\hline $\mathrm{R}$ & \multicolumn{5}{|l|}{0.978} \\
\hline Adjusted R Square & \multicolumn{5}{|l|}{0.954} \\
\hline F hitung & \multicolumn{5}{|l|}{419.58} \\
\hline Probabilitas signifikan F & \multicolumn{5}{|l|}{0.000} \\
\hline
\end{tabular}

Sumber : Data primer diolah

Uji Asumsi Klasik. Nilai VIF untuk masing-masing variabel bebas lebih dari 5 artinya bebas multikolineritas. Nilai DW sebesar 1.833 diantara du=1,74 dan 4 -du = 2,26 artinya tidak terjadi autokorelasi. Sedangkan probalilitas residual untuk masing-masing variabel bebas terhadap variabel tergantung menunjukkan tidak signifikan yakni lebih besar dari nilai a $(0,05)$ artinya bebas heteroskedastisitas.

Model Regresi berganda. Model yang dihasilkan adalah $Y=7,244+0,475 X_{1}+0,057$ $\mathrm{X}_{2}+0,385 \mathrm{X}_{3}+$ e. Berdasarkan uji $\mathrm{F}$ bahwa model regresi berganda yang dihasilkan diterima sebagai alat analisis terbukti dari nilai $\mathrm{F}$ hitung $(419,48)$ lebih besar dari $\mathrm{F}$ tabel $(3,967)$. Untuk menguji hubungan ketiga variabel bebas dengan variabel tergantung digunakan analisis korelasi berganda (R). Hasil analisis diperoleh koefesien korelasi berganda (R) sebesar 0,978 berarti ada hubungan yang sangat kuat diantara variabel Harga (X1), Kualitas Pelayanan $\left(\mathrm{X}_{2}\right)$, dan Kemudahan $\left(\mathrm{X}_{3}\right)$ dengan Loyalitas Petani Tebu $(\mathrm{Y})$ di Kabupaten Malang Bagian Selatan. Sedangkan koefisien determinasi ganda (Adjusted R²) sebesar 0,954 
menunjukkan besarnya kontribusi variabel bebas terhadap variabel tergantung sebesar $95,4 \%$, sisanya sebesar 4,6 \% merupakan kontribusi dari unsur/variabel lain yang tidak termasuk dalam model. Hasil koefisien korelasi berganda (R) dan koefisien determinasi ganda menunjukkan bahwa secara teoritis variabel bebas pada penelitian ini dinilai sangat akurat untuk menerangkan dan memprediksi variabel Loyalitas Petani tebu di lingkungan Kabupaten Malang.

Uji parsial. Nilai Prob. Sig. t untuk masing-masing variabel bebas seperti variabel harga (X1) dan kemudahan (X3) lebih kecil dari nilai a $(0,05)$ artinya variabel harga dan kemudahan secara parsial berpengaruh signifikan terhadap loyalitas petani tebu, sedangkan variabel kualitas pelayanan (X3) tidak memberikan pengaruh signifikan terhadap loyalitas petani tebu $(Y)$. Nilai koefisien variabel harga sebesar 0,475 lebih besar dari nilai koefisien regresi variabel bebas lainnya, artinya variabel Harga (X1) berpengaruh dominan terhadap Loyalitas Petani Tebu (Y).

\section{PEMBAHASAN}

Perilaku loyal petani tebu. Secara keseluruhan perilaku petani tebu dinilai baik tentang loyalitasnya kepada PG Krebet Baru. Nampak bahwa dari tahun ke tahun secara rata-rata PG Krebet Baru mengalami kenaikan pasokan bahan baku tebu. Dukungan dan harapan petani tebu untuk menggunakan jasa PG Krebet Baru dinilai baik. Tujuh item pengukuran tentang perilaku loyalitas petani tebu di Kabupaten Malang Bagian Selatan seperti kesediaan untuk mengirim hasil panen tebu ke PG Kreber Baru, perasaan senang sebagai pemasok di PG Krebet Baru, kesediaan menceritakan kebaikan tentang PG Krebet baru, kesediaan mengikuti aturan main, petunjuk/arahan, memahami tentang kesulitan PG Krebet Baru, serta mau menyampaikan keluhan kepada PG Krebet Baru disimpulkan bahwa dari ketujuh item tersebut yang mendapat respon baik dari para petani tebu yakni kesediaan petani tebu untuk selalu mengirim hasil panennya ke PG Krebet Baru dan kesediaan petani tebu untuk melakukan serta mengikuti petunjuk dan arahan dari pihak manajemen PG Krebet Baru. Hal ini nampak bahwa petani tebu menyambut baik program PG Krebet Baru seperti program PG Krebet Baru seperti aplikasi ZPK, sistem ARI (Analisis 
Rendemen Individu) yang dikenal dengan penetapan rendemen per truk, program sistem kontrak, serta program insentif bagi pemasok tebu yang diberlakukan pada masa giling 2007 lalu.

Keterkaitan kebijakan harga pasok, kualitas pelayanan dan kemudahan terhadap loyalitas petani tebu. Ketiga variabel yang diukur mempunyai hubungan yang sangat erat / kuat dengan loyalitas petani tebu ditunjukkan dengan nilai multiple korelasi sebesar 0,978. Kontribusi ketiga variabel bebas yakni penetapan harga, kebijakan kualitas layanan dan kebijakan kemudahan PG Krebet Baru memberikan sumbangan yang besar terhadap tingkat loyalitas petani tebu. Sehingga pernyataan Irawan (2002:37-76) yang menyatakan bahwa faktor-faktor loyalitas dapat dipengaruhi oleh kebijakan harga, kualitas pelayanan dan kemudahan terbukti di lingkungan para petani tebu di wilayah Kabupaten Malang bagian selatan terhadap kebijakan PG Krebet Baru.

Faktor-faktor yang mempengaruhi loyalitas petani tebu sebagai pemasok bahan baku tebu PG Krebet Baru yakni faktor kebijakan harga pasokan dan faktor kemudahan. Faktor kebijakan harga pasok seperti kebijakan penetapan harga gula dan rendemen memberikan pengaruh yang signifikan terhadap tingkat loyalitas petani tebu. Petani tebu merasa aman jika kadar rendemen ditetapkan secara obyektif dan memihak kepada petani, sehingga para petani merasa aman untuk bercocok taman tebu dan tebu memberikan prospek yang baik untuk masa depan mereka. Petani setuju dengan penetapan rendemen melalui sistem ARI yang diberlakukan mulai periode giling 2007 hingga kini. Penetapan sistem ARI oleh petani memberikan dampak baik terhadap hasil keuangan panen mereka.

Kebijakan kualitas layanan PG Krebet Baru ternyata tidak memberikan dampak signifikan terhadap loyalitas petani tebu. Petani tebu sering kena sanksi rafaksi pada lokasi timbangan. Aturan ketat PG Krebet Baru menurut pemikiran petani perlu ditinjau kembali. Disamping itu petani tebu masih menyangsikan akurasi timbangan tebu. Petani tebu berharap ada tranparansi tentang keakuratan timbangan tebu. Banyak kejadian seperti tebu petani di tolak oleh PG Krebet karena kendala di lapangan seperti tidak tersedianya SPTA (Surat Perintah Tebang Angkut), sehingga petani tebu mengambil jalan pintas untuk menjual tebunya pada para pedagang. Kejadian ini menimbulkan persepsi dari petani tebu 
bahwa seolah-olah petugas lapangan dinilai kurang handal dalam mengatasi persoalan petani tebu. Ironisnya para pedagang juga dengan mudah memperoleh SPTA (Surat Perintah Tebang Angkut). Barangkali ini adalah kendala hubungan langsung antara PG Krebet Baru dengan para petani tebu. Perlu dilakukan penataan yang lebih akuntable untuk membangun sistem antara kebutuhan petani tebu dan PG Krebet Baru.

Faktor kemudahan memberikan dampak positip terhadap loyalitas petani tebu seperti kemudahan dalam memperoleh bibit tebu dan kemudahan untuk sewa traktor. Kemudahan bagi petani tebu dianggap sangat penting terutama penyediaan pupuk yang akhir-akhir ini mengalami kelangkaan. Petani sangat bergantung terhadap pupuk kimia dibanding pupuk organik. Sehingga untuk merubah pola tanam membutuhkan waktu yang cukup lama. Harapan petani adalah adanya kebijakan pabrik yang dapat menyelesaikan kesulitan para petani tebu serta dapat memberikan rasa aman bagi mereka.

\section{KESIMPULAN DAN SARAN}

Pengaruh kebijakan harga pasok, kualitas layanan dan kemudahan yang diberikan oleh perusahaan secara simultan memberikan pengaruh terhadap perilaku loyal bagi petani tebu di Wilayah Malang Selatan. Pada penelitian ini ditemukan bahwa penetapan harga pasok seperti penetapan harga gula dan rendemen mempengaruhi perilaku loyal petani tebu, sehingga perusahaan harus cukup hati-hati dalam menetapkan kebijakan harga dan rendemen dalam sistem ARI. Kualitas layanan yang diberikan oleh perusahaan tidak berpengaruh terhadap loyalitas petani tebu hal ini disebabkan karena petani sering/merasa kena sanksi rafaksi di lokasi timbangan. Disarankan peraturan tentang tebu masuk supaya ditinjau ulang dan tidak memberatkan petani tebu. Disamping itu petani masih menyangsikan akurasi timbangan tebu. Petani berharap adanya keterbukaan tentang akurasi timbangan tebu. Disarankan sistem kalibrasi supaya lebih terbuka. Selain itu ketersediaan SPTA (Surat Perintah Tebang Angkut) masih menjadi kendala bagi petani, karera tidak tersedia sistem / kebijakan yang jelas dari pabrik kepada petani, sehingga petani banyak yang bergantung kepada pedagang. Disarankan supaya manajemen pabrik 
lebih dekat dengan petani dan memahami persoalan petani sehingga penjatahan SPTA tidak mengalami tumpang-tindih antara petani dan pedagang.

\section{DAFTAR PUSTAKA}

Anonim. 2002. Company Profile. PT PG Rajawali / Unit PG Krebet Baru Malang Ancok,Djamaludin. 1997. Teknik Penyusunan Skala Pengukur. PPK UG. Yogyakarta Ferdinand, Augusty. 2006. Metode Peneliian Manajemen. Badan Penerbit UNDIP. Semarang

Ghozali Imam , 2001. Aplikasi Analisis Multivariate. Undip. Semarang

Indrajit, Richardus Eko. 2006. Konsep Manajemen Supply Chain. PT Gramedia. Jakarta

Indrayani, Emmy. 2004. Loyalitas Merek sebagai Dasar Strategi Penentuan Harga. Jurnal Ekonomi dan Bisnis.Fakutas Ekonomi.Nomor 3 Jilid 9. Universitas Gunadarma.Depok

Irawan. 2007. Memahami Kepuasan dan Loyalitas Pelanggan. PT Elexmedia Komputer. Jakarta.

Kotler, Philip, 1997. Marketing Management. Ninth Edition. Printice Hall International. New Jersey

Kotler, Philip. 1995. Manajemen Pemasaran, Analisis, Perencanaan, Implementasi dan Pengendalian. Jilid II Edisi V. Penerbit Erlangga.. Jakarta 2003. Manajemen Pemasaran. Jilid I. Edisi terjemahan. PT Intan Sejati. Klaten

Munawaroh, Munjiati, 2000. Timbulnya Gab antara Kinerja dengan Harapan Kualitas Jasa dapat Mempengaruhi Tingkat Kepuasan Pelanggan, Jurnal Ekonomi Univ. Merdeka Malang, No 5, Oktober 2000

Malhotra, Naresh,K,1996. Marketing Research, Printice Hall International Industri, London

Mc Carthy, Dennis G, 1997. The Loyalty Link, New York; John Wiley \& Sons

Morgan R.M e Hunt S.D, 1994. The Commitment-Trust Theory of Relationship Marketing,"Journal of Marketing", July, 20-38

Mowen. H. 2001. Perilaku Konsumen. Jilid I. Penerbit Andi Yogyakarta.

Nirwanto Nasief, 2000. Karyawan loyal mencipta kepuasan pelanggan, Jurnal Ekonomi Univ. Merdeka Malang, No. 5, Oktober 2000 
Nurdiansah, Erwin.2003. Analisis Model Hubungan antara Dimensi Kualitas Jasa dengan Dimensi Loyalitas Jasa pada Industri Jasa Murni (Perbankan) dan Jasa Campuran (Fast Food) di Kota Malang. Tesis. Malang.Universitas Brawijaya

Oliver, Richard. 1996. Satisfaction a Behaviour Prespective on The Customer. Mc Graw Hill, New York.

\section{Gramedia. Jakarta}

2005.Strategi Manajemen Pembelian dan Supply Chain.PT

Parasuraman; Zeitham, AV Berry LL, 1985. A Conceptual Modul Of Service Quality and Its Implications for Future Research, dalam Subiyakto, tahun 1999, Ukuran Kualitas Jasa : Gap antara Kinerja dan Harapan, Jurnal Uasahawan Vol. 2 No 1: 19-30

Payne Adrian.2000. The Essence of Services Marketing. Pemasaran Jasa. Terjemahan Fandy Tjiptono. Prentince Hall. International. UK

Rahayu, Yayuk Sri. 2003. Analisis Pengaruh Dimensi Kualitas Jasa terhadap Kepuasan dan Loyalitas Mahasiswa. Tesis. Malang. Program Pascasarjana Universitas Brawijaya.

Sanusi Anwar, 2003. Metodologi Penelitian Praktis. Buntara Media Malang

Santoso, Singgih. 2000. Aplikasi Excell dalam Statistik Bisnis. PT Elexmedia Komputer. Jakarta.

Simamora, Henry. 2000. Manajemen Pemasaran Internasional. Cetakan pertama.Salemba Empat. Jakarta

Sugiono, 2000. Metode Penelitian Administrasi. Edisi enam. Cetakan kelima. CV Alfabeta. Bandung

Tjiptono, Fandy.2002. Strategi Pemasaran. Edisi Kedua. Cetakan kedua, Penerbit Andy Yogyakarta

--2004. Pemasaran Jasa. Edisi Pertama. Cetakan Pertama. Bayumedia Publishing. Malang

Yamit, Zulian. 2002. Manajemen Kualitas Produk dan Jasa. Penerbit Ekonesia Yogyakarta. 